\title{
Diagnostic and treatment problems with parosteal osteosarcoma. A clinical and a histological study of 7 cases and review of the literature
}

\section{Milan Samardziski ${ }^{1}$, George Zafiroski ${ }^{1}$, Cveta Tolevska ${ }^{2}$, Slavica Konstadinova-Kunovska ${ }^{3}$, Violeta Vasileva ${ }^{4}$}

\author{
${ }^{1}$ University Clinic for Orthopedic Surgery-Skopje, \\ ${ }^{2}$ Institute for Radiotherapy and Oncology-Skopje, ${ }^{3}$ Pathology Institute-Skopje, \\ ${ }^{4}$ University Surgical Clinic "St. Naum Ohridski" - Skopje
}

\begin{abstract}
Background. Parosteal osteosarcoma is a rare low-grade bone tumour. The operation material must undergo a careful patohistological analysis, because the extent of invasion of the medullar cavity and most probably the extent of dedifferentiated areas determines the prognosis and occurrence of local recurrence and metastases.

Patients and methods. In this retrospective clinical study, 7 cases of parosteal osteosarcoma of the bone have been analyzed. Six patients were with parosteal osteosarcoma and one with periosteal osteosarcoma. The study was performed at the Clinic for Orthopedic Surgery in Skopje, Macedonia, from 1995 to 2006. This tumour represents 1.5\% of all 467 patients with primary bone tumours treated at the Clinic in the 12 year period. The age of 7 patients ( 3 female and 4 male) ranged from 8 to 39 years (median 27). The history analysis of the patients showed the misinterpreted diagnosis in $57 \%$ of the cases, with $71.4 \%$ rate of local recurrence, $28.7 \%$ of metastases and $28.7 \%$ of mortality. The follow-up varied from 7 months to 9 years (median 37 months).

Results. The clinical and histopathological findings of this study (same as those reviewed in the literature) confirmed the occurrence of two biologically different types of parosteal osteosarcoma: the predominant type is originally "benign" but has a definite malignant potential, causing metastases after the long symptom-free interval. The other type is highly malignant from the beginning.

Conclusions. The compartmental, radical "en bloc" resection, followed by the regular review of the patients, is recommended for the low malignant type, however, the radical surgery, followed by chemotherapy, is recommended for the highly malignant tumours.
\end{abstract}

Key words: osteosarcoma - diagnosis - therapy; periosteum

Received 1 August 2007

Accepted 7 August 2007

Correspondence to: Milan Samardziski MD, MSc, University Clinic for Orthopaedic Surgery, University "St. Cyril and Methodius", Vodnjanska 17, 1000 Skopje, Macedonia; Phone/Fax: + 38923176 672; E-mail: milan_samardziski@yahoo.com

\section{Introduction}

Parosteal osteosarcoma is a rare low-grade bone tumour. It was apparently described for the first time in 1951 by Geschickter and Copeland, regarding the initial confusion 
with the terminology. ${ }^{1,2}$ It occurs between the $2^{\text {nd }}$ and $7^{\text {th }}$ decade of life and it represents 1,6 to $2 \%$ of all malignant bone tumours. ${ }^{3}$ The most frequent location is the distal dorsal femur. Until clearly proven otherwise, a boneforming tumour in this localisation must be regarded as parosteal osteosarcoma. To determine the histopathological diagnosis could be "tricky". The tumour is characterised by hyalinized fibrous stroma with low cell content without substantial nucleus polymorphism and variably dense bony trabeculae. The operation material must undergo a careful patohistological analysis, because the extent of invasion of the medullar cavity and most probably the extent of dedifferentiated areas determines the prognosis and occurrence of local recurrence and metastases. ${ }^{4,5}$

As most authors report, a wide margin of excision ensures the adequate surgical treatment of parosteal osteosarcoma in any surgical grade or stage. No evidence for the development of primary tumour satellite nodules or of "skip" metastases were seen, so it would seem that truly radical or compartmental surgery is rarely indicated. The significant incidence of pulmonary metastasis among those patients with Grade III parosteal osteosarcoma and involvement of the medullar cavity, suggests that, for them, adjuvant chemotherapy should be considered. ${ }^{3,4,6,7}$ The primary wide excision may be less effective for the local recurrence where there has been a previous inadequate biopsy or surgical treatment, because of the contamination and spread of the tumour into the surrounding tissues. ${ }^{7}$

The tumour is most commonly misinterpreted as osteochondroma or heterotrophic ossification and even large institutions have limited experience of its diagnosis and management. ${ }^{4}$ Parosteal osteosarcoma shows, like no other tumour, the necessity of close cooperation of all involved disciplines for diagnosis and therapy and should be treated only in specialized institutions for bone tumour surgery.

\section{Patients and methods}

At the re-examination of the records at the Clinic for Orthopedic Surgery in Skopje, during the last 12 years (from 1995 to 2006), 7 cases of juxtracortical osteosarcoma were found. Five of them were patients with parosteal osteosarcoma and one patient was with periosteal osteosarcoma. Parosteal osteosarcoma represented 1.5\% of all 467 patients with malignant bone tumours treated in this time at the Clinic.

Reviewing the records, bone scans with Technetium 99m, radiographs, arteriography, CT, MRI and histopathology findings showed 6 patients with the confirmed diagnosis of parosteal osteosarcoma and one was with a high grade chondroblastic type of periosteal osteosarcoma. Four of them were diagnosed and treated at the Clinic for Orthopedic Surgery in Skopje and 3 patients started their treatment elsewhere and were misdiagnosed for osteochondroma. Another three started their treatment as unspecified malignant tumour of distal femur and only one was primarily suspected to be parosteal osteosarcoma.

\section{Results}

The clinical details of all 7 patients are summarized in Table 1.

\section{Age and sex}

The age ranged from 8 to 39 years (median 27). There were 3 female and 4 male patients.

\section{Site of the tumour}

In 4 cases the site of tumour was the posterior surface of the distal femur. In 1 case primary site of tumour was postero-medial surface of the proximal femur. In 1 case the site of tumour was proximal humerus and 
Table 1. Clinical details of the 7 cases

\begin{tabular}{|c|c|c|c|c|c|}
\hline $\begin{array}{l}\text { Case / } \\
\text { initials }\end{array}$ & Sex & Age & Site of the tumor & $\begin{array}{l}\text { Duration of } \\
\text { symptoms } \\
\text { (months) }\end{array}$ & Symptoms \\
\hline $\begin{array}{l}1 . \\
\text { VM }\end{array}$ & $\mathrm{F}$ & 28 & Proximal tibia & 13 & Painless tumour \\
\hline $\begin{array}{l}2 . \\
\mathrm{BT}\end{array}$ & M & 27 & Distal femur & 15 & Blunt pain and tumour \\
\hline $\begin{array}{l}3 . \\
\mathrm{BS}+\end{array}$ & M & 8 & Distal femur & 9 & Blunt pain and tumour \\
\hline $\begin{array}{l}4 . \\
\text { SV }\end{array}$ & $\mathrm{F}$ & 39 & Distal femur & 17 & Painless tumour \\
\hline $\begin{array}{l}5 . \\
\text { ID }\end{array}$ & M & 24 & Proximal femur & 13 & Painless tumour \\
\hline $\begin{array}{l}6 . \\
\text { JM }\end{array}$ & M & 17 & Proximal humerus & 8 & $\begin{array}{l}\text { Severe pain tumour and } \\
\text { reduction of movements }\end{array}$ \\
\hline $\begin{array}{l}7 . \\
\text { RM }\end{array}$ & $\mathrm{F}$ & 32 & Distal femur & 11 & Blunt pain and tumour \\
\hline median & & 27 & median & 13 & \\
\hline
\end{tabular}

\section{Legend}

MSTSS - Musculoskeletal Tumor Society Score ${ }^{7}$;

MMA - reconstruction of the defect with metilmet-acrilate (bone cement);

Resection arthrodesis- reconstruction with intramedular nail and MMA;

STE - special tumour endoprosthesis;

† - lethal outcome.

in 1 case the site of tumour was the posterior surface of the proximal tibia.

\section{Symptoms}

The most frequent sign on admission at the Clinic was localized painless swelling present in 3 patients, progressively increasing blunt pain and swelling was present in 3 patients and severe "night pain", swelling and restriction of movements was present in 1 patient. The duration of the symptoms varied from 8 to 17 months (median 13).

\section{Radiological findings}

In 4 cases the radiographs showed a densely ossified and lobulated mass on the posterior mataphysial cortex of the distal femur (Figure 1a). Similar dense and lobulated tumours were seen at the other sites. Tumours were attached to the bone by broad base (Figure 
Treatment

1. radical resection $+\mathrm{MMA}$

1. resection

2. reresection

3. amputation

1.resection arthrodesis

2. recurrence excision

1. resection arthrodesis

2. STE.

1. resection and STE.

2. disarticulation after masive Neo-adjuvant

local recurrence

1. radical resection +

nonvascular fibular graft

1. "en bloc" resection

2. radical resection $+\mathrm{STE}$

After Oper.

Neo- adjuvant

After Oper.

No

\section{Chemotherapy}

$\begin{array}{ll}\text { After Oper. } & \begin{array}{l}\text { After } 3 \\ \text { months }\end{array}\end{array}$

After 3 months

After 32 months

No

71

39

After 61 months

No

Neo- adjuvant No

No

7

38

median 1a, 1c). In one case, after the recurrence, two thirds of the circumference of the distal femoral metaphysis were involved (Figure 1b). This patient was considered to have medullar involvement on CT scans (Figure 3a).

\section{Pathological findings}

The tumours were ossified with occasional soft areas, all of them infiltrating the surrounding soft tissues. Most of them had typical histological appearance of a low grade parosteal osteosarcoma, with spindle cells and collagen fibers embedding osseous trabeculae. The spindle cell stroma was scarcely cellular, with low to moderate atypia of the cells, as well as low mitotic activity. The trabeculae were rather regularly arranged, but missing the osteoblastic rimming. Two of the cases also showed cartilaginous islands in the mainly fibroblastic tumour tissue (Figure $2 a)$. Most of the cases had well (G1) to moderate (G2) degree of differentiation (Figure 2b).

Only one presented a high grade chondroblastic (G3) surface osteosarcoma. It was presented as a high grade surface chondroblastic osteosarcoma (case 3 , Table 1), with scarce and hard to find foci of osteoid and wide areas of malignant cartilage. The tumour cells showed marked polymorphism and high mitotic index (Figure 2c). Recurrent lesions usu- 

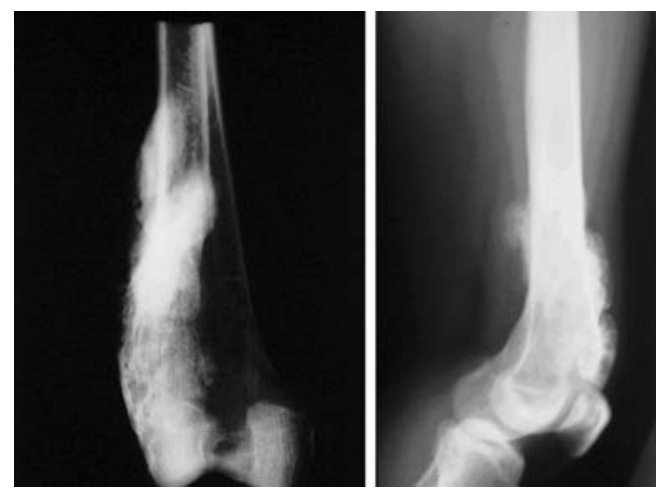

Figure 1a. Frontal and lateral radiography of the parosteal osteosarcoma of right distal femur (case 2).

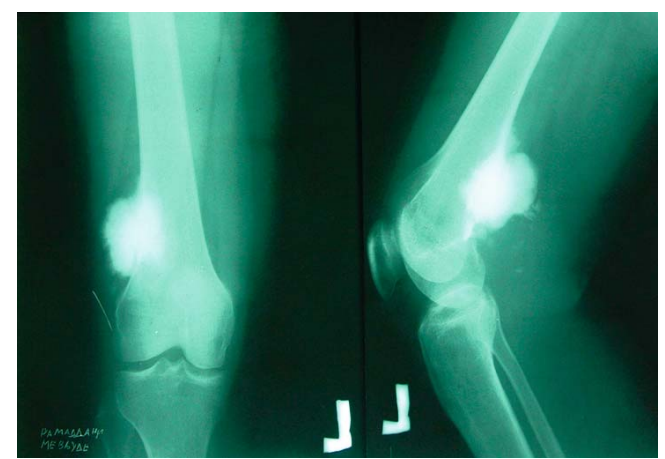

Figure 1b. Frontal and lateral radiography of the parosteal osteosarcoma of right distal femur (case 7).

ally showed less differentiation than the primary tumours.

\section{Medullar involvement}

In 7 patients managed, 1 had the initial histological medullar involvement and 2 patients had the medullar involvement after the local recurrence (Figure 3a). For two patients who were treated out of the Clinic for Orthopaedic Surgery in Skopje initially, it was not possible to tell due to the lack of evidence (Figure 3b, 3c). Only one patient didn't have the medullar involvement at all (case 6).

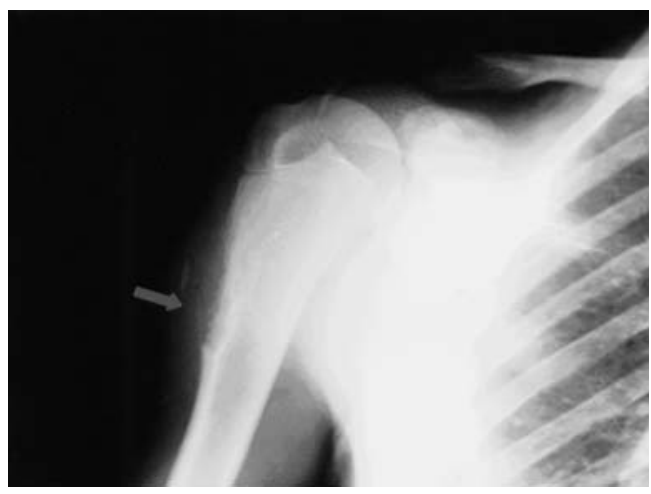

Figure 1c. X-ray of parosteal osteosarcoma of the right proximal humerus (case 6).

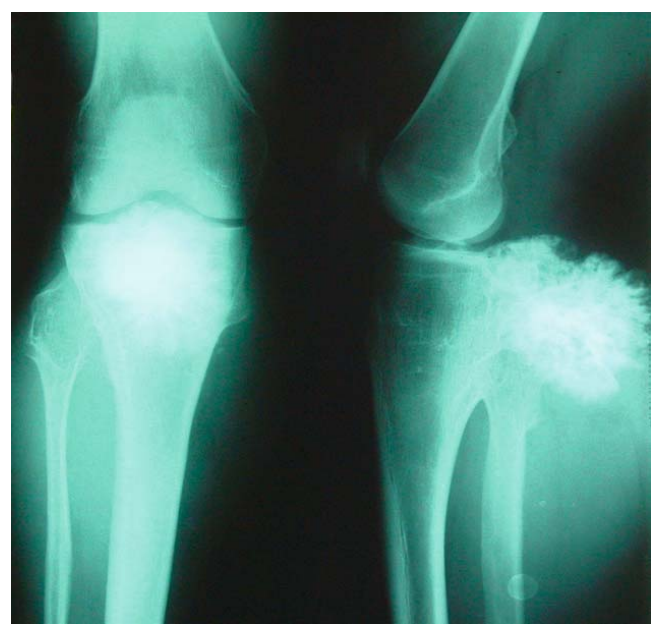

Figure 1d. X-rays of parosteal osteosarcoma of the proximal tibia (case 1).

\section{Discussion}

Parosteal osteosarcoma is a rare malignant bone tumour first described by Geschickter and Copeland in 1951.1,2,8, $9 \mathrm{Up}$ to date, there are reports of parosteal osteosarcoma even in human pets. ${ }^{10}$ Larsson and Lorentcon found only 206 cases (including sixteen cases from their study) to be reported until 1980 in the world literature. ${ }^{11}$ The annual incidence in Sweden, as they reported, corresponds to one case per 8000000 inhabitants and were accounted for about $2 \%$ of all primary malignant 


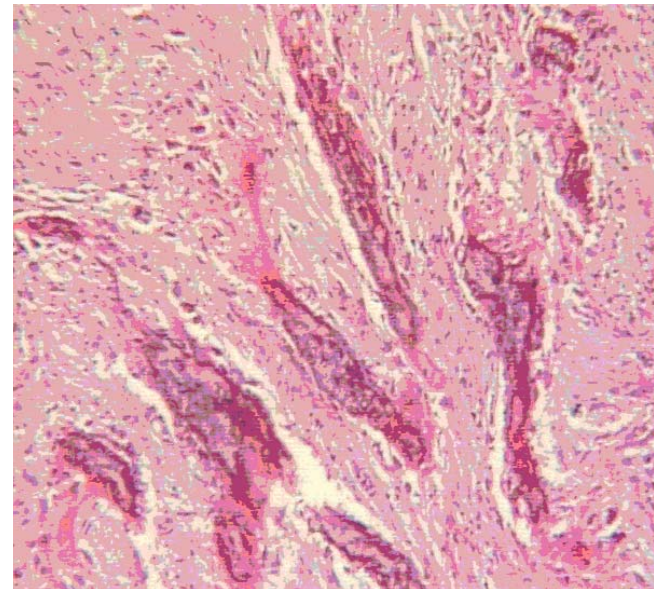

Figure 2a. Parosteal osteosarcoma showing parallel osteoid trabeculae embedded in fibroblastic stroma. HE, x100.

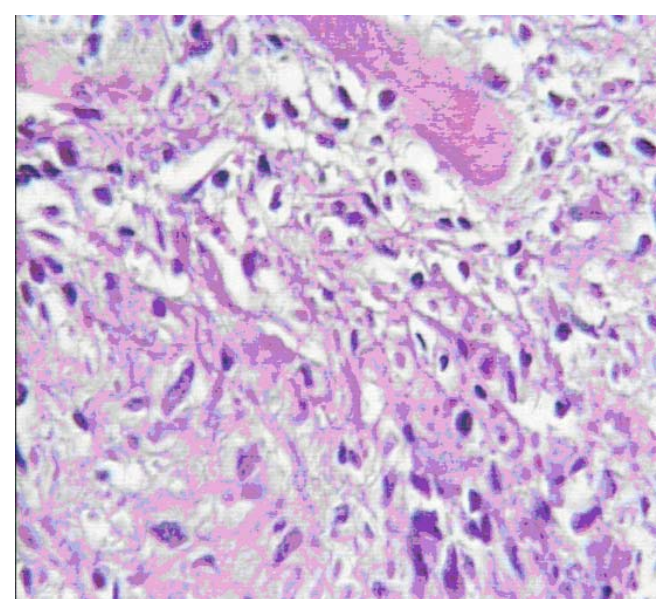

Figure $\mathbf{2 b}$. Focus of a moderate grade of differentiation (G2) in a well differentiated osteosarcoma. HE, x200.

tumours of bone and $6.2 \%$ of all osteosarcomata. In comparison, Dahlin reported that parosteal osteosarcoma constituted only $3.7 \%$ of all osteosarcomata from Mayo Clinic. $3,11,12$

Most of the world studies documented difficulties in the diagnosis of parosteal osteosarcoma. The inability to diagnose the lesion correctly often leads to inadequate initial operative procedures. The differential diagnosis may include diverse entities

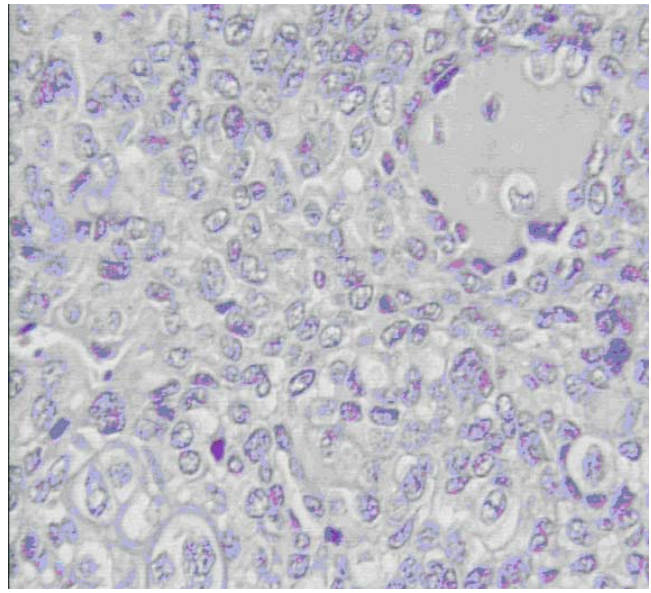

Figure 2c. Osteoid deposits in high grade chondroblastic osteosarcoma. HE, x400.

such as: myositis ossificans, fracture callus, ossifying haematoma, osteochondroma, extraosseus osteosarcoma, parosteal chondroma, desmoplastic fibroma and osteoma. ${ }^{3,4,5,7,13}$

The clinical characteristic of patients who have a parosteal osteosarcoma is distinctly different from that of patients who have conventional osteosarcoma. ${ }^{2,13}$ The most common complain was "painless swelling", the same as reviewed in the literature, presented with 3 patients., 3,7,8,12 Two of our patients had "blunt pain with swelling" and one had "night pain". Most of our patients had the symptoms of prolonged duration more than one year before admitting at the Clinic.

The site of the parosteal osteosarcoma in our study correlates with the reported sites of the literature. A predilection for anatomic site was a characteristic feature of the patients in the study and showed that 50\% of the patients in our study had the involved posterior part of distal metaphysis of the femur. ${ }^{4,6,9,14,15}$

The well described concept of dedifferentiated parosteal osteosarcoma with higher incidence of development of metastases 


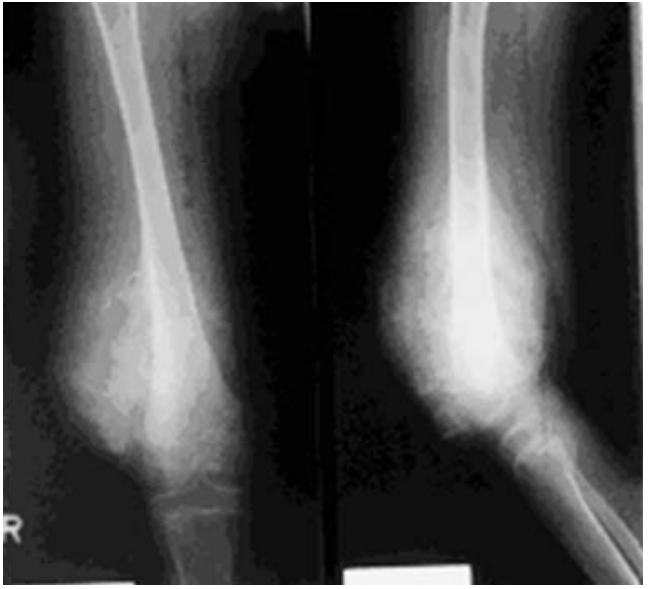

Figure 3a. frontal and lateral radiography of local recurrence of "high grade" chondroblastic type periosteal osteosarcoma (case 3).

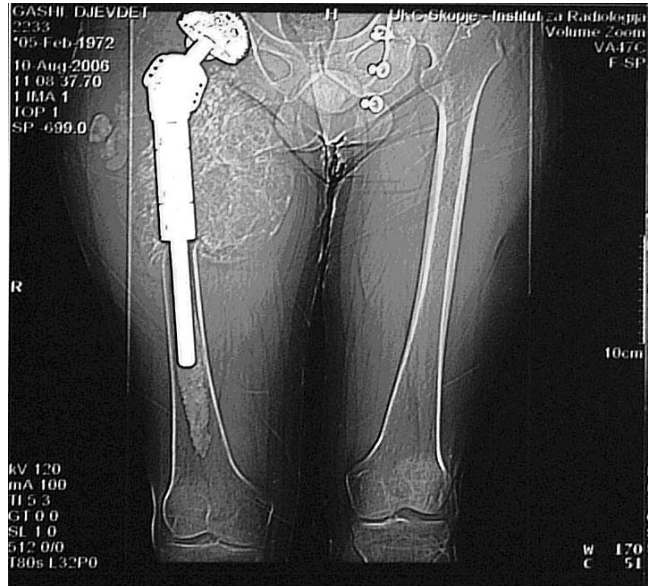

Figure 3c. Radiograph of the recurrence of parosteal osteosarcoma at the proximal femur after limb salvage operation with special tumor endoprosthesis (case 5).

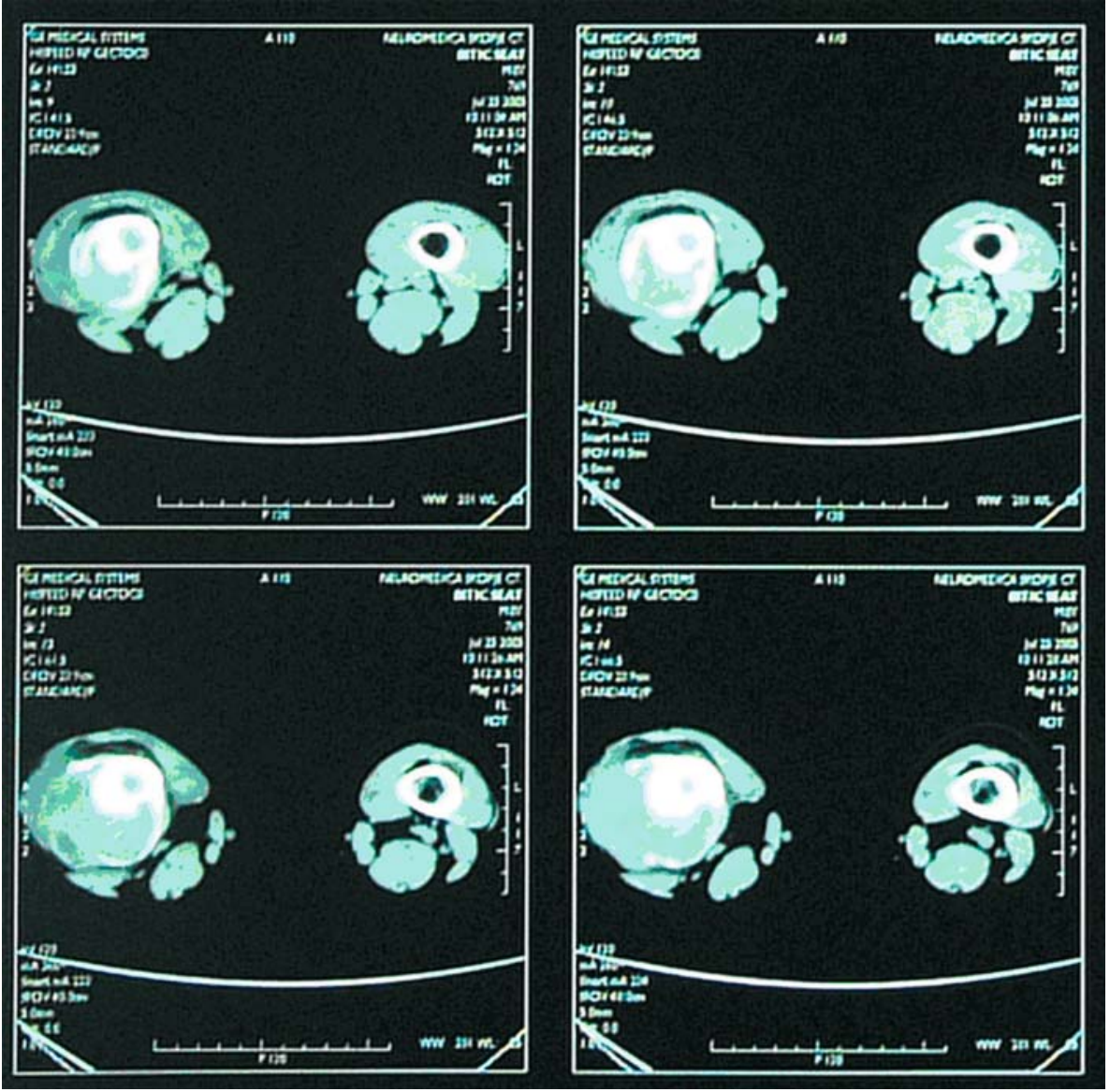

Figure $3 \mathbf{b}$. CT of distal femur showing the extent of medullar involvement of the bone (case 3 ). 
is also applicable in our study. ${ }^{3,5,16,17}$ The dedifferentiation of the tumour showed the high incidence with pulmonary metastases in one of our patients. A long-term follow up is essential for assessing the real malignant potential of parosteal osteosarcoma since the recurrence can be considerably delayed. ${ }^{18}$

The results of various types of therapy are always difficult to evaluate in retrospect. A review of the literature shows that the local excision of the tumours has almost invariably resulted in recurrence. $3,6,9,13,17,18$ The local recurrence was not related to the medullar involvement of the tumour but to the number or adequacy of biopsies and surgical margins of the resection of the tumour. ${ }^{14,19}$ Two of the patients had more than one, and one patient had three inadequate placed biopsies. Further more, three of the patients in our study had the intralesional or inadequate marginal resection of the tumour during the primary surgical treatment. Over all results were poor to fair and varied from 25 to 39 points of MSTS score. ${ }^{20}$

\section{Conclusions}

The findings of this study followed the theory that two distinct types of parosteal osteosarcoma exist: one type, which is primarily highly malignant and the other one, which is originally benign but with the inherent malignant potential. Only two patients of our study had modern chemotherapy and this did not allow any definite conclusion. In most of the cases the histopathological diagnosis was a problem at the beginning of the treatment. For well delineated tumours with a well-differentiated histological appearance, the radical (en block) resection of the tumour and surrounding soft tissue is strongly recommended. In patients with advanced tumours contain- ing pleomorphic areas and/or inadequate placed biopsies or prior inadequate surgical treatment, the amputation should be undertaken. Parosteal osteosarcoma shows, like no other tumour, the necessity of the close cooperation of all involved disciplines for the diagnosis and therapy and should be treated only in specialized institutions for bone tumour surgery.

\section{References}

1. Geschickter CF, Copeland MM. Parosteal osteosarcoma of bone: a new entity. Ann Surg 1951; 133: 579-83.

2. Gross SW. The classic: sarcoma of the long bones: based upon a study of one hundred and sixty-five cases. 1879. Clin Orthop Relat Res 2005; 438: 9-14.

3. Lorentzon R, Larsson SE, Boquist L. Parosteal (juxtracortical) osteosarcoma. A clinical and histopathological study of 11 cases and review of the literature. J Bone Joint Surg Br 1980; 62-B: 86-92.

4. Campanacci M, Picci P, Gherlinzoni F, Guerra A, Bertoni F, Neff JR. Parosteal Osteosarcoma. J Bone Joint Surg Br 1984; 66: 313-21.

5. Deling, D, Werner M. Pathomorphologie des parossalen osteosarcoms. Erfahrungen an 125 fällen des Hamburger Knochentumor-Registers. Orthopäde 2003; 32: 74-81.

6. Bacci G, Picci P, Ferrari S, Sangiorgi L, Mercuri $\mathrm{M}$, Bertoni F, et al. Neoadjuvant chemotherapy for the treatment of osteosarcoma of the extremities: excellent response of the primary tumor to preoperative treatment with methotrexate, cisplatin, adriamycin, and ifosfamide. Preliminary results. [English, Italian]. Chir Organi Mov 1995; 80: $1-10$.

7. Bertoni F, Boriani S, Campanacci M. Periosteal osteosarcoma and periosteal chondrosarcoma. Two distinct entities. J Bone Joint Surg Br 1982; 64: 370-6.

8. Lichtenstein L. Bone tumors. $4^{\text {th }}$ edition. Saint Louis: CV Mosby Company; 1972.

9. Scaglietti O, Calandriello CB. Ossifying parosteal osteosarcoma. Parosteal osteoma or juxtacortical osteogenic sarcoma. J Bone Joint Surg Am 1962; 44A: $635-47$. 
10. Thomas WB, Daniel GB, McGavin MD. Parosteal osteosarcoma of the cervical vertebra in a dog. Vet Radiol Ultrasound 1997; 38: 120-3.

11. Larsson SE, Lorentzon R. The geographic variations of the incidence of malignant primary bone tumors in Sweden. J Bone Joint Surg Am 1974; 56-A: 592-600.

12. Pritchard DJ, Finkel MP, Reilly CA Jr. The etiology of osteosarcoma. A review of current considerations. Clin Orthop Relat Res 1975; (111): 14-22.

13. Okada K, Frassica FJ, Sim FH, Beabout JW, Bond JR, Unni KK. Parosteal osteosarcoma. A clinicpathological study. J Bone Joint Surg Am 1994; 76: 366-78.

14. Kavanagh TG, Cannon SR, Pringle J, Stoker DJ, Kemp HB. Parosteal osteosarcoma. Treatment by wide resection and prosthetic replacement. J Bone Join Surg Br 1990; 72: 959-65.

15. Kumm DA.; Rütt J. Hakenbroch MH. Parosteal osteosarcoma of the tarsus. Arch Orthop Trauma Surg 1997; 116: 437-9.

16. Haeckel C, Ayala AG, Radig K, Raymond AK, Roessner A, Czerniak B. Protease expression in dedifferentiated parosteal osteosarcoma. Arch Pathol Lab Med 1999; 123: 213-21.

17. Ritschl P, Wurnig C, Lechner G, Roessner A Parosteal osteosarcoma. 2-23-year follow-up of 33 patients. Acta Othop Scand 1991; 62: 195-200.

18. Lau TW, Wong JW, Yip DK, Chien EP, Shek TW, Wong LL. Local recurrence of parosteal osteosarcoma adjacent to a prosthesis after 20 years: a case report. J Orthop Surg 2004; 12: 263-6.

19. Lewis VO, Gebhardt MC, Springfield DS. Parosteal osteosarcoma of the posterior aspect of the distal part of the femur: oncological and functional results following a new resection technique. J Bone Joint Surg Am 2000; 88-A: 1083-8.

20. Enneking WF, Dunham W, Gephardt MC, Malawar M, Prichard DJ. A system for functional evaluation of reconstructive procedures after surgical treatment of tumours of the musculoskeletal system, Clin Orthop 199; 286: 241-6. 